\title{
EDITORIAI \\ Hyogo Declaration and the Cultural Map of the World
}

\author{
Frederick M. Burkle, Jr, MD, MPH, DTM
}

Citizens around the world are engaged, trained and empowered to act.

Arthur L. Kellerman, MD, MPH

F. Edward Hébert School of Medicine,

Uniformed Services University of the Health Sciences

A fter the Great Hanshin-Awaji earthquake of 1995 and the 2004 tsunami disaster in the Indian Ocean, the United Nation's International Strategy for Disaster Reduction sponsored the World Conference on Disaster Reduction, which was hosted by Japan in 2005. Its heralded product, the Hyogo Declaration, challenged governmental and non-governmental experts worldwide to find ways to reduce the increasing toll of disasters, primarily through prevention and preparedness. ${ }^{1}$ The adoption of the international Early Warning Program was one of its many accomplishments. The Hyogo Framework for Action (HFA-1), signed by 168 countries, called for a 10-year plan to spur building the resilience of nations and communities to disasters. Specific actions focused on disaster risk reduction (DRR), improving risk information and early warning, building a culture of safety and resilience, reducing risks in major sectors, and strengthening preparedness for response. Noteworthy for Japan was the development in 2011 of the International Research Institute of Disaster Science (IRIDeS) of Tohoku University and its Disaster Medical Science Division.

In the 10 years since HFA 1 , many events have affected the way the world looks at disaster events. Inextricably, across the entire planet, its geographical regions, nationstates, and communities, "disasters define the public health while exposing its vulnerabilities." ${ }^{2}$ With today's rapid advances in communication capabilities and capacity, those vulnerabilities have been revealed almost instantaneously to a global population. What have not kept pace are the expectations for sustainable prevention, mitigation, preparedness, and response for an increasingly wary global population. In fact, those capabilities may now be at an all-time low.

The reasons for the current state of affairs are many. The impact of compromised public health infrastructure and systems on health consequences greatly influences the manner in which disasters are observed, planned for, and managed, especially ones that are geographically widespread, population dense, and prolonged. $^{3}$ What may first result in direct injuries and death may rapidly change to indirect illness and subsequent excess morbidity and mortality, as essential public health resources are destroyed, deteriorate, or systematically denied to vulnerable populations.

One of the major advances in disaster and crisis science has been that disasters and public health are now inseparably linked. It is ironic that in the current cultural map of the world "standards of living show that health status, life expectancy, child survival, democratization and political participation, literacy and matriculation, and gender equality are at their best," ${ }^{4}$... while the "critical masses of evidence indicate that the frequency, duration, and intensity of major disasters affecting populations are on the rise." Moreover, the most vulnerable are the "have not" populations that are relegated, not by choice, to primarily occupy the most disaster-prone areas especially in rapidly urbanized and population dense conclaves of the world where public health protections are scarce. Decisions to do otherwise are more mired in raw economics than in the health of nations. Meanwhile, public health itself is slowly being redefined less by traditional health indices systematically documented by the World Health Organization and its regional health organizations and increasingly by a nation-state's capacity to provide its population with arable land, food, water, and energy.

Clearly, these major shortcomings will occupy the minds of health practitioners and policy makers anticipating the World Conference on Disaster Reduction scheduled for Sendai, Japan, in March 2015. Supporting the agenda of the new Hyogo Framework for Action (HFA-2) was the International Symposium for Disaster Medical and Public Health Management: Review of the Hyogo Framework for Action, a regional symposium that was held in Washington, DC, in May of 2014. It was designed and supported by IRIDeS, the Japan Society for the Promotion of Science, the Tohoku University School of Medicine and Health Sciences, the George Washington University, the Center for Disaster and Humanitarian Assistance Medicine of the Uniformed Services University of Health Sciences in Bethesda, Maryland, and the Children's National Health System in Washington, DC. The symposium focused on health-specific disaster risk reduction (DRR) proposals, identifying gaps in the HFA 1 related to the topic of health, and producing substantive recommendations for the 2015 world conference. 
How to persuasively articulate these concerns into plausible recommendations for the upcoming 2015 Hyogo Declaration in Sendai proved uncomfortable for many. Although many attendees were at ease talking about response, they were challenged by world body organizations, delegates from the Centers for Disease Control and Prevention (CDC), and representatives of academic think tanks who patiently instilled prevention, preparedness, DRR, and disaster risk management (DRM) taxonomy and concepts into the conversation. This gap, which is intensely generational and cultural, was more universal than we thought. Understanding that long-term investment in prevention and preparedness, DRR, and DRM is more economically sound and effective than response alone has been slow to comprehend. Restive attendees, appreciating that too many developing countries have not yet witnessed the benefits of an effective response phase, have argued for equal attention to both.

Also disconcerting for the delegates was to learn that a major flaw in the outcomes of the 2005 Hyogo Declaration and HFA 1 was that health was not effectively promoted as a priority. In fact, the term health was only used 3 times in HFA 1 and only twice in the pre-HFA 2 draft. Health and public health advocates have had to struggle to make their case. However, the strong preamble of this regional symposium made clear that its outcome should work to effectively alter the diplomatic landscape and bring health as an imperative for DRR in the 2015 Hyogo Declaration debates.

Under the auspices of delegates primarily from Japan and the United States and with guidance from multiple world bodies and disaster experts, several months of discussions, debates, and planning preceded the 2-day regional symposium. Breakout sessions, which were organized under the crosscutting principle that "health integration is imperative for disaster risk reduction in the Hyogo Framework for Action," concluded their work within 5 subthemes:

- Frameworks and principles relating to medical preparedness and health management in disasters;

- Health planning for all phases of a disaster, including risk assessment with concern for vulnerable populations;

- Psychosocial/mental health concerns and building community resilience;

- Infrastructure and logistics; and

- Education and training.

Health advocates, within the stated outcomes of this regional symposium, will need to become major contributors in both measuring progress in critical DRR and assisting countries and organizations in responding to reporting requirements that had been presented and met by the United Nations International Strategy for Disaster Reduction (UNISDR) system in the HFA (2005-2015). Specifically, Arturo Pesigan, $\mathrm{MD}$, a technical officer in the Emergency and Humanitarian Action unit of the Regional Office for the Western Pacific of WHO, asserted that an explicit outcome of the new global framework on DRM must emphasize sectors that are vital for managing disaster risks, including health, education, and agriculture. In addition, it must ensure safe hospitals as a global priority for action, so that new and existing health facilities remain operational in emergencies and disasters and that the post-2015 HFA refers to best practice approaches to DRM (eg, comprehensive, multisectorial, community-based, all-hazards approaches), human rights, and humanitarian principles. In other words, the global framework must be multidisciplinary.

Terje Skavdal, chief of the Field Coordination Support Service of the UN Office for the Coordination of Humanitarian Affairs (UNOCHA) implored that opportunities be presented to leverage OCHA's coordination mechanisms in major disaster events to establish linkages with various actors in the humanitarian field including national health systems. In addition, Mark Keim, associate director for science at the CDC, highlighted the critical value of DRR measures in dealing with root causes of disasters and reducing human suffering and saving lives. He strongly emphasized that, in comparison to response and recovery, DRR measures are more cost-effective, community-based, and more sustainable. Also, in her closing remarks, Virginia Murray, FRCP, FRCPath, vice-chair of the UNISDR Science and Technical Advisory Group, commended the participants on the impressive messages emerging from the symposium and emphasized the need to share these important messages with other partners to enhance the communication to support the decision making of policy makers and other stakeholders.

The researchers of IRIDeS and the Japanese government perceive that the greatest challenges in the coming world conference may be the metrics to evaluate risk reduction. Shinichi Egawa, $\mathrm{MD}, \mathrm{PhD}$, professor of International Cooperation for Disaster Medicine at IRIDeS, spoke on the challenges and outcomes that arose from the work of the symposium. He reflectively stated that "...the symposium was a great advantage for us to be visible in the larger stage of risk reduction. The chance that health will be included in DRR has improved. However, the scientific evidence to prove or measure the efficacy of health improvement will be necessary over what exists today. It is mandated that we establish credible evidence based initiatives similar to what has advanced other sectors of medicine." He pondered the situation again and added, "But, many challenges to health and its acceptance in DRR will continue" (oral communication, August 18, 2014).

\section{About the Author}

Harvard Humanitarian Initiative, Harvard University, Cambridge, MA; and Woodrow Wilson International Center for Scholars, Washington, DC.

\section{REFERENCES}

1. Hyogo Declaration. World Conference on Disaster Reduction, January 18-22, 2005, Kobe, Hyogo, Japan. New York, NY: United Nations International Strategy for Disaster Reduction; 2005. http://www.unisdr. 
org/2005/wcdr/intergover/official-doc/L-docs/Hyogo-declaration-english.pdf. Accessed August 18, 2014.

2. Burkle FM Jr. Redefining the Public Health of Nations [slide presentation]. Honolulu, Hawaii: Center of Excellence in Disaster Management and Humanitarian Assistance; 1993.

3. Burkle FM Jr., Martone G, Greenough PG. The changing face of humanitarian crises. Brown J World Affairs. 2014; 20(11):25-42. http:// hhi.harvard.edu/sites/default/files/publications/BROWN\%20JOURNAL\%
20HUM\%20CRISES\%20BURKLE\%20MARTONE\%20GRRENOUGH \%202014.pdf. Accessed August 18, 2014.

4. Garfield RM, Polonsky JJ, Burkle FM Jr. Changes in size of populations and level of conflict since World War II: implications for health and health services Disaster Med. Public Health Prep. 2012; 6(3):241-246.

5. Intergovernmental Panel on Climate Change. Managing the Risks of Extreme Events and Disasters to Advance Climate Change Adaptation. New York, NY: Cambridge University Press; 2012. 